\title{
ANALISA KUALITAS OLI TERHADAP JARAK TEMPUH OPERASIONAL DAN EMISI GAS BUANG MESIN SEPEDA MOTOR MENGGUNAKAN MINYAK JARAK (CASTOR OIL) DENGAN PENAMBAHAN OIL ADDITIVE (HEXAGONAL BORON NITRIDE DAN CERAMIC TECHNOLOGY)
}

\author{
Mohammad Iqbal, Dr. Ir. M. Sabri, MT. IPM. Asean Eng. \\ Departemen Teknik Mesin, Fakultas Teknik, Universitas Sumatera Utara \\ Mohammadilubis@gmail.com
}

\begin{abstract}
ABSTRAK
Pelumasan memiliki peranan penting pada mesin dan peralatan yang didalamnya terdapat suatu komponen yang saling bergesekan yaitu sebagai pengaman agar tidak terjadi kerusakan yang fatal. Pelumas bio berbasis minyak nabati dapat memenuhi semua tuntutan baik dari fungsi maupun lingkungan. Saat ini regulasi emisi Euro IV sudah mulai diberlakukan sejak 2018 lalu tentang baku mutu emisi gas buag kendaraan bermotor. Kondisi seperti itu yang menuntut produsen pelumas di penjuru dunia harus menciptakan minyak pelumas yang sesuai standart Euro IV. Banyak produsen minyak pelumas yang mengembangkan dari bahan dasar mineral menggantinya menjadi bahan dasar nabati. Namun secara langsung tidak dapat dilakukan karena memiliki nilai kekentalan kinematik yang rendah dibandingkan dengan minyak bumi mineral dengan begitu harus dicampur dengan aditif untuk menaikan sifat kekentalan minyak nabati pada pengujian ini. Pada penelitian ini mesin uji yang digunakan yaitu mesin 4- langkah SOHC dengan 2-katup pada sepeda motor Honda Revo Fit 110 cc tahun 2018. Minyak jarak murni dan yang ditambahkan aditif digunakan secara langsung sebagai oli pelumas sampai jarak operasional mesin masing-masingnya $1125 \mathrm{~km}$. Tujuan dari pengujian untuk mengetahui kinerja minyak pelumas dan penurunan kualitas dari oli pelumas. Hasil dari penelitian mengalami Keadan minyak pelumas setelah pemakaian mengalami penurunan rapat massa pada suhu $40^{\circ} \mathrm{C}$ dan $100^{\circ} \mathrm{C}$ setelah jarak tempuh operasional dari mesin, rapat massa sebesar 591,99 kg/m3 menjadi 436,92 kg/m3 pada suhu $40^{\circ} \mathrm{C}$ dan $563,87 \mathrm{~kg} / \mathrm{m} 3$ menjadi $413,09 \mathrm{~kg} / \mathrm{m} 3$ pada suhu 100. Untuk kekentalan kinematik mengalami penurunan yang cukup signifikan pada suhu $40^{\circ} \mathrm{C}$ maupun suhu $100^{\circ} \mathrm{C}, 51,43 \mathrm{cSt}$ menjadi $42,31 \mathrm{cSt}$ pada suhu $40^{\circ} \mathrm{C}$ dan mengalami kenaikan $16,72 \mathrm{cSt}$ menjadi $22,36 \mathrm{cSt}$ pada suhu $100^{\circ} \mathrm{C}$ untuk minyak nabati murni. Untuk nilai pH mengalami penurunan dari dari pH 7,8 menjadi 5,7 yang sudah mendekati asam kuat oli pelumas sudah harus diganti. Pengambilan sampel oli sebanyak $10 \mathrm{ml}$ disetiap jarak tempuh $75 \mathrm{~km}$ sampai jarak pengujian $1125 \mathrm{~km}$ membuat oli berkurang sebanyak $150 \mathrm{ml}$.
\end{abstract}

Kata kunci: Pelumasan, Energi Terbarukan, Gesekan

\section{PENDAHULUAN}

Pelumasan memiliki suatu peranan yang penting pada suatu mesin dan peralatan yang didalamnya terdapat suatu komponen yang saling bergesekan yaitu sebagai pengaman agar tidak terjadi kerusakan yang fatal. Pelumasan memiliki fungsi dan guna yang sangat menentukan panjang pendeknya umur mesin. Fungsi dari pelumasan itu sendiri adalah mengurangi adanya gesekan antara metal dan komponen-komponen mesin lainnya sehingga dapat meminimalkan resiko terjadinya kerusakan pada mesin.. (Effendi, 2014: 1 )

Untuk patokan memperpanjang umur mesin maka pergantian oli dilakukan secara teratur

1. Dino oil (mineral) : antara $2000 \mathrm{~km} \mathrm{~s} / \mathrm{d} 3000 \mathrm{~km}$ 
2. Synthetic Based Oil (Semi Synthetic) : antara $3000 \mathrm{~km} \mathrm{~s} / \mathrm{d} 5000 \mathrm{~km}$

3. Fully-Synthetic Oil : antara $5000 \mathrm{~km} \mathrm{~s} / \mathrm{d} 7000 \mathrm{~km}$

\section{TINJAUAN PUSTAKA}

\subsection{Gesekan Dan Keausan}

Gesekan adalah hambatan gerak selama meluncur atau bergulir, yang dialami suatu permukaan bergerak secara berlawanan di atas yang lain yang dengannya terjadi kontak. Gaya tangensial resistif, yang bertindak dalam arah yang berlawanan dengan arah gerak, disebut gaya gesek. Ada dua jenis gesekan utama yang sering dijumpai: gesekan kering dan gesekan cairan. Seperti namanya, gesekan kering, juga disebut friksi "Coulomb", menggambarkan komponen tangensial dari gaya kontak yang ada saat dua permukaan kering bergerak atau cenderung bergerak relatif satu sama lain. Gesekan cairan menggambarkan komponen tangensial dari gaya kontak yang ada di antara lapisan yang berdekatan pada fluida yang bergerak pada kecepatan yang berbeda relatif terhadap satu sama lain seperti pada cairan atau gas di antara permukaan bantalan. (Bhushan, 2013:199)

\subsection{Kekentalan Dinamik Dan Kekentalan Kinematik}

Dalam industri perminyakan khususnya minyak pelumas dikenal istilah kekentalan, karena kekentalan merupakan sifat paling penting bagi minyak pelumas khususnya dan bahan pelumas umumnya, karena sifat ini menunjukkan kemampuan untuk melumasi sesuatu dan kemampuan suatu fluida untuk mengalir. Pada gambar 2.4 menunjukkan pendefenisian kekentalan dinamik. menurut Hukum Newton tentang aliran viskos. Suatu permukaan bergerak relatif dengan kecepatan u terhadap permukaan lain dimana diantara kedua permukaan ditempatkan suatu lapisan tipis fluida. Kekentalan didefenisikan sebagai besarya tahanan fluida untuk mengalir di bawah pengaruh tekanan yang dikenakan dan besarnya harga kekentalan merupakan perbandingan antara tegangan geser yang bekerja dengan kadar geseran . (Shigley, 2008: 599)

\subsection{Indeks Kekentalan}

Indeks viskositas (Viscosity Index, VI) adalah suatu ukuran dari perubahan viskositas terhadap temperatur. Viskositas pelumas akan turun jika temperature naik dan sebaliknya, viskositas akan naik jika temperature turun. Perubahan ini tidak akan sama untuk semua pelumas. Saat ini hampir semua pelumas memiliki VI yang cukup tinggi, diatas 100 sehingga perubahan temperatur tidak merubah viskositas hingga ke tingkat yang membahayakan mesin. Semua pelumas jenis multi grade memiliki VI diatas 100. (Fajar, 2007: 13)

Dalam penentuan indeks kekentalan minyak pelumas kekentalannya pada $210^{\circ} \mathrm{F}$ 
$\left(100^{\circ} \mathrm{C}\right)$ dan $100^{\circ} \mathrm{F}\left(40^{\circ} \mathrm{C}\right)$ pertama - tama diukur terlebih dahulu. Jika minyak pelumas yang tidak diketahui indeks kekentalannya mempunyai kekentalan $\mathrm{U}(\mathrm{cSt})$ pada $100^{\circ} \mathrm{F}\left(40^{\circ} \mathrm{C}\right)$ dan kedua minyak pelumas VI $=0$ dan VI $=100$ mempunyai.

$$
V I=\frac{L-U}{L-H} \times 100
$$

\section{METODOLOGI PENELITIAN}

\subsection{Desain Parameter}

Untuk menentukan suatu kajian minyak pelumas memenuhi standart keamanan atau tidak maka diperlukan adanya penentuan parameter yang digunakan dalam suatu kajian. Parameter inilah yang kemudian menentukan standart karakteristik kajian yang harus dipenuhi untuk mencapai nilai layak penggunaan dalam aktivitas sehari hari. Maka kemudian dalam kajian Analisa kualitas oli terhadap jarak tempuh operasional dan emisi gas buang mesin sepeda motor menggunakan minyak jarak (castor oil) dengan penambahan Oil Additive dan Ceratec Liqui Moly untuk memenuhi standart emisi Euro IV ditentukan dengan parameter yang berpengaruh.

\subsection{Identifikasi Parameter}

Kekentalan (viskositas) minyak pelumas merupakan petunjuk yang sangat penting sebagai ukuran fisik kemampuan minyak pelumas. Nilai kekentalan minyak pelumas merupakan kemampuan memberikan ketahanan terhadap gerakan relative dari bagian bagian yang akan diakumulasi. Selain kekentalan, nilai pH juga sangat menentukan kualitas minyak pelumas. Sehingga nilai $\mathrm{pH}$ berpengaruh besar terhadap kualitas minyak pelumas yang digunakan. Nilai pH tetap harus dijaga agar fungsi minyIdeak pelumas tetap berjalan baik dan dapat digunakan sebagai mana mestinya. Sehingga kajian eksperimental dari Analisa kualitas oli terhadap jarak tempuh operasional dan emisi gas buang mesin sepeda motor menggunakan minyak jarak (castor oil) dengan penambahan Oil Additive dan Ceratec Liqui Moly adalah; massa jenis ( $\rho)$, kekentalan/viskositas (v), indeks kekentalan (VI), waktu (t), keasaman (pH), dan hasil penguapan dalam mesin sehingga berpengaruh pada emisi gas buang yang berbahaya yaitu karbon monoksida (CO) dan hidro karbon (HC)

\subsection{Variabel Penelitian}

Dalam penelitian analisa minyak jarak dengan campuran aditif maka penulis membagi ada menjadi 2 variabel yaitu variable tetap dan variable bebas

\subsubsection{Variabel Tetap}

- $\quad$ Densitas ( $\rho)$ : Massa Jenis atau Rapatan

- Indeks kekentalan (VI) :Perubahan nilai viskositas akibat perubahan temperatur 
- $\quad$ Tingkat keasaman dan kebasaan (pH) : Perubahan nilai pH pada minyak pelumas.

- Karbon monoksida (CO) : Gas buang kendaraan bermotor

- Hidro Karbon (HC) : Campuran gas untuk pembakaran

\subsubsection{Variabel Bebas}

- Suhu udara luar : Suhu saat dilakukan pengujian

- Kekentalan kinematic (v) : Rasio viskositas absolut dengan kepadatan

\section{DATA PENGUJIAN DAN ANALISA}

\subsection{Data Perhitungan Rapat Massa (Density) Minyak Pelumas}
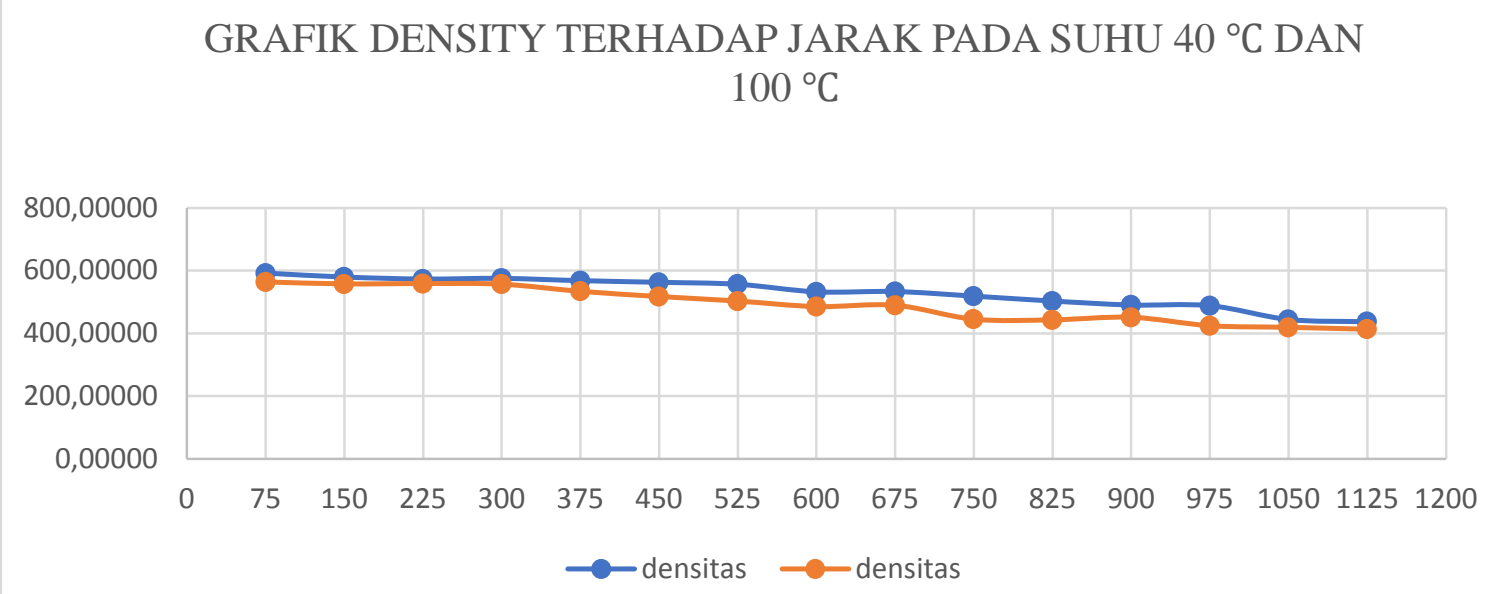

Gambar 4.1 Grafik Perhitungan Rapat Massa Minyak Pelumas

- $\quad$ Terjadi gerakan penurunan grafik dari minyak jarak (castor oil) dengan penambahan Oil Additive And Ceratec Liqui Moly dari setiap titiknya pada suhu $40^{\circ} \mathrm{Cmaupun}$ suhu $100^{\circ} \mathrm{Csetelah}$ pengujian

4.2 Data Pengujian Kekentalan Minyak Jarak (Castor Oil) dan Oil Additive And Ceratec Liqui Moly 


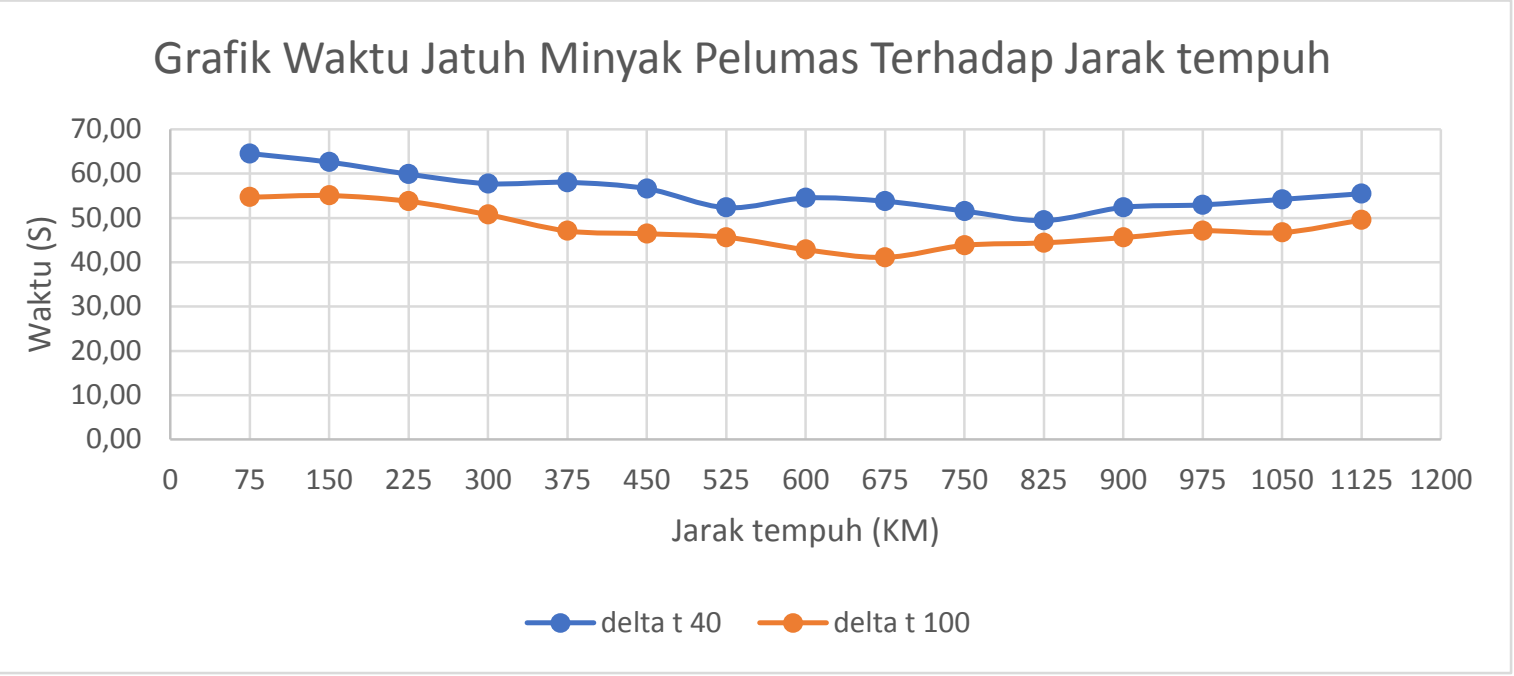

Gambar 4.2 Grafik Waktu Jatuh Minyak Pelumas Terhadap Jarak Tempuh

- Minyak jarak menggunakan zat aditif lebih menjaga kekentalan daripada minyak jarak murni dari sebelum pengujian hingga setelah dilakukan pengujian.

\subsection{Data Viskositas Kinematik Terhadap Jarak Tempuh}

\section{Gafik Viskositas Kinematik Terhadap jarak Tempuh}

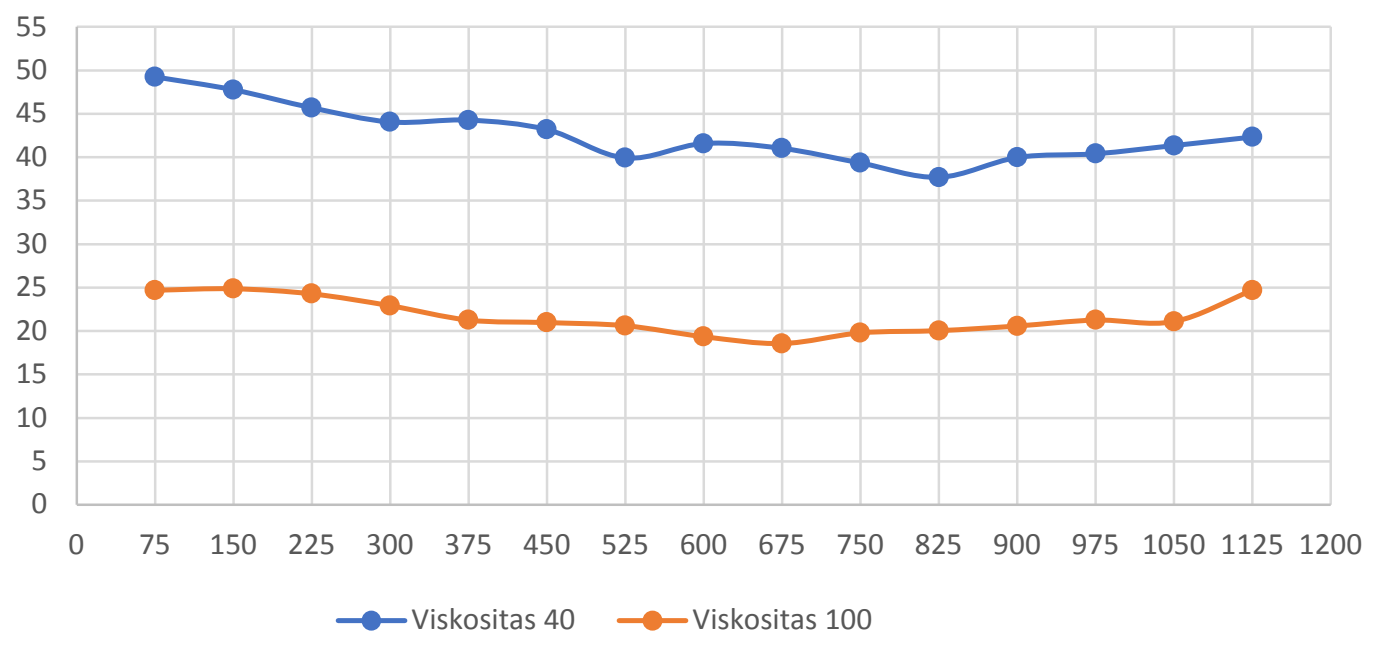

Gambar 4.3 Grafik Viskositas Kinematik Terhadap Jarak Tempuh

- Minyak jarak menggunakan zat aditif lebih mampu menahan kekentalan kinematic daripada minyak jarak murni dikarenakan zat aditif yang terkandung menjaga kekentalan dan tidak cepat menjadi lumpur (sludge)

\subsection{Data Indeks Viskositas}




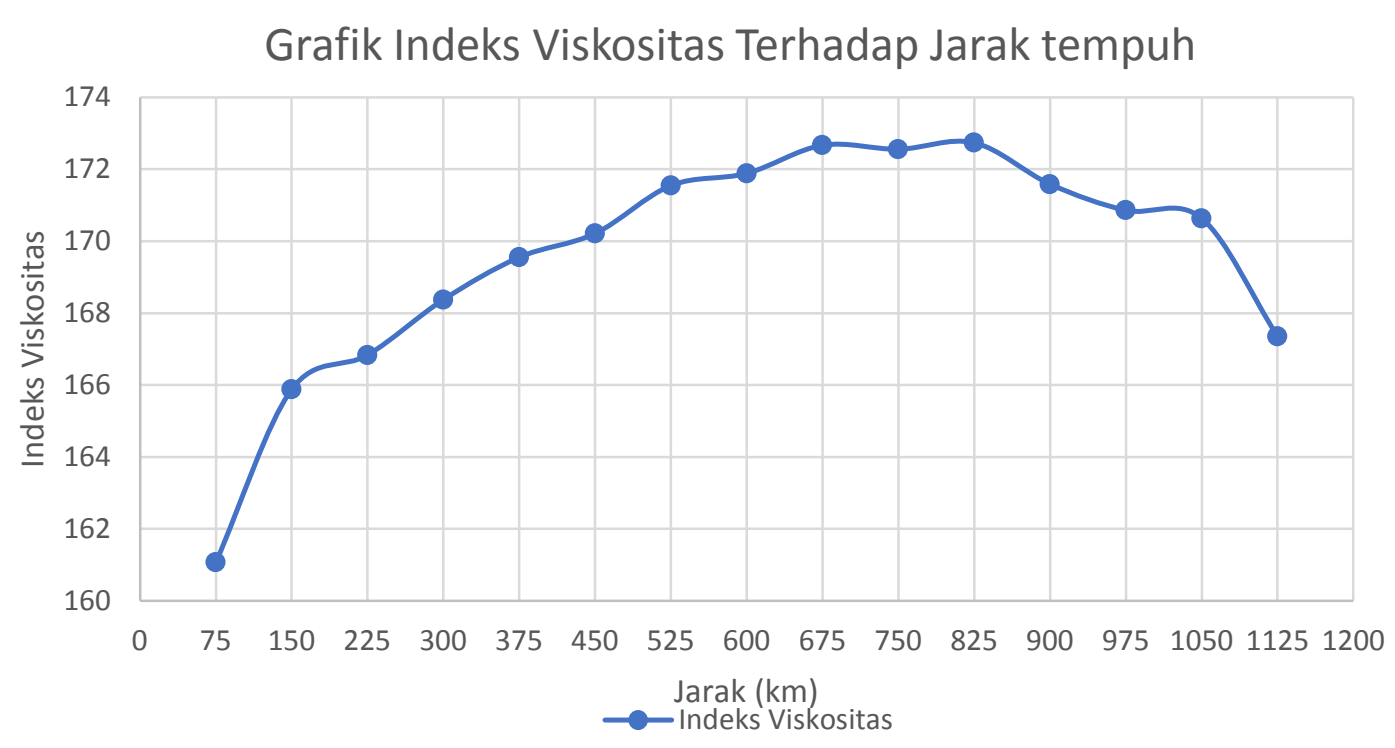

Gambar 4.4 Grafik Indeks Viskositas

- Pada jarak 825 km - 1125 km mengalami penurunan nilai indeks viskositas dikarenakan sudah berkurangnya lapisan film pada zat aditif yang terkandung pada minyak tersebut.

- Indeks viskositas dapat berubah sewaktu - waktu karena perubahan suhu yang ekstrim dan lingkungan sekitar

- Dari keseluruhan nilai grafik indeks viskositas bahwa zat aditif sangat membantu dalam menjaga kekentalan miyak pelumas didalam mesin

\subsection{Data pH Minyak Pelumas}

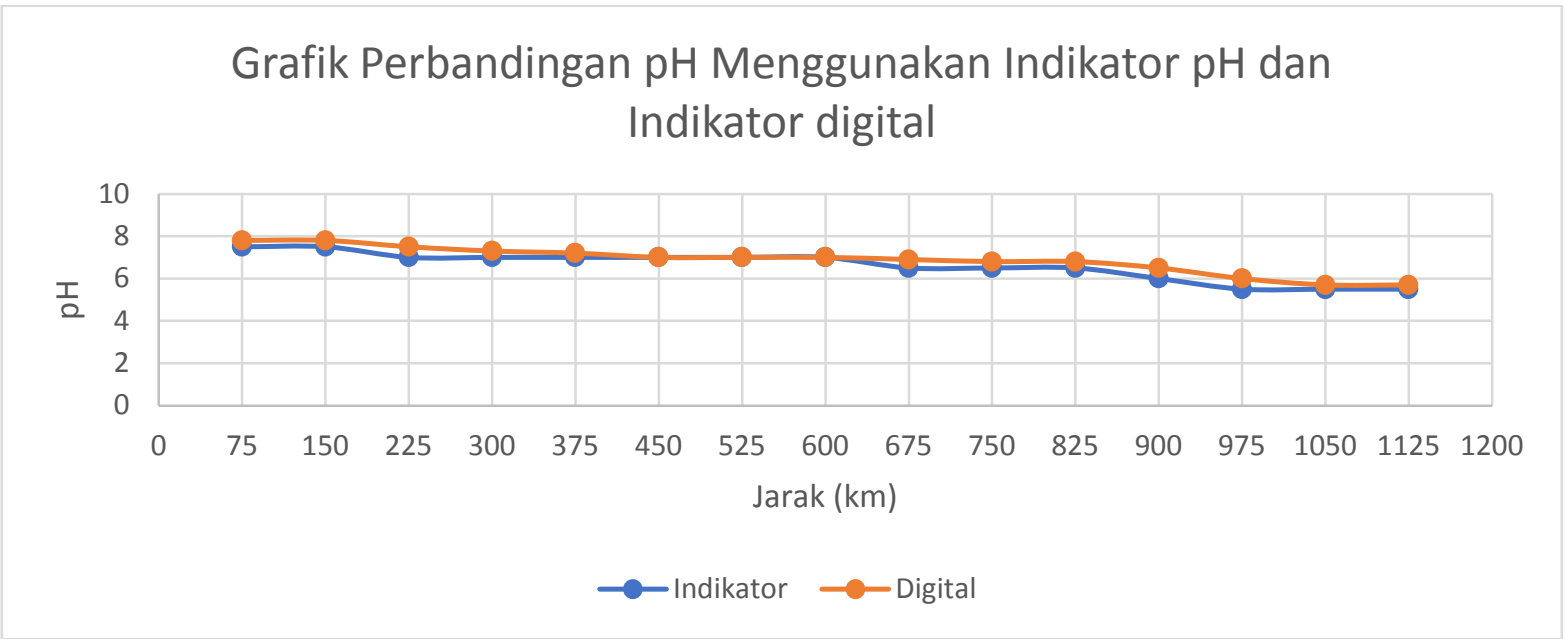

Gambar 4.4 Grafik Perbandingan pH Menggunakan Indikator pH dan Indikator Digital

- Terjadi penurunan grafik secara berkala selama jarak operasional pada pengujian yang dilakukan. 
- $\quad$ Zat aditif sangat membantu dalam menjaga nilai pH karena bersifat mengurangi oksidasi terhadap minya itu sendiri

\subsection{Hasil Emisi Gas Buang Menggunakan Gas Analyzer}

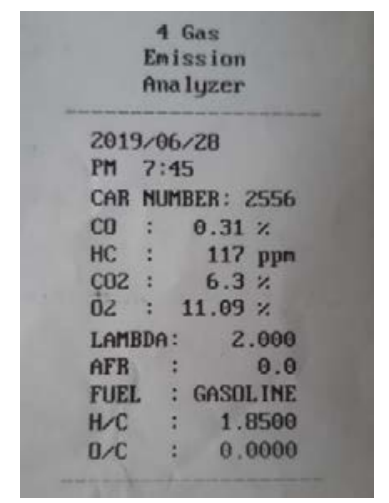

Gambar 4.5 Hasil Emisi Gas Buang Menggunakan Gas Analyzer

- Dalam uji emisi gas buang gas yang berbahaya adalah CO dan HC. Kedua gas ini berbahaya bagi manusia dan lingkungan. Nilai maksimal dalam standart emisi gas buang Euro III untuk gas CO adalah 1\% dan nilai maksimal gas HC adalah 300 ppm. Maka jika kedua gas kurang dari itu dinyatakan layak dan bisa dimodivikasi menjadi standart emisi gas buang standart Euro IV

- Hasil pengujian gas CO2 dan O2 di atas sangat tinggi. Itu terjadi karena adanya kesalahan atau bocor pada knalpot sehingga menyebabkan nilai gas $\mathrm{CO} 2$ dan $\mathrm{O} 2$ tinggi.

\section{KESIMPULAN DAN SARAN}

\subsection{Kesimpulan}

1. Minyak jarak (castor oil) dengan penambahan Oil Additive And Ceratec Liqui Moly yang digunakan sebagai oli pelumas pada mesin 4-langkah sepeda motor Revo Fit 110 cc dari hasil pengujian didapatkan bahwa mengalami kestabilan kekentalan sampai 825 km dan menurun kualitas oli yaitu bertambahnya tingkat kekentalan dan densitas, penurunan nilai indeks viskositas, dan penurunan nilai pH pada jarak 825 km keatas.

2 Keadan minyak pelumas setelah pemakaian mengalami penurunan rapat massa pada suhu $40^{\circ} \mathrm{C}$ dan $100^{\circ} \mathrm{C}$ setelah jarak tempuh operasional dari mesin, rapat massa sebesar 591,99 $\mathrm{kg} / \mathrm{m}^{3}$ menjadi $436,92 \mathrm{~kg} / \mathrm{m}^{3}$ pada suhu $40^{\circ} \mathrm{C}$ dan $563,87 \mathrm{kgm}^{3}$ menjadi $413,09 \mathrm{~kg} / \mathrm{m}^{3}$ pada suhu 100. Untuk kekentalan kinematik mengalami penurunan yang cukup signifikan pada suhu $40^{\circ} \mathrm{C}$ maupun suhu $100^{\circ} \mathrm{C}$. 51,43 cSt menjadi 42,31 cSt pada suhu $40^{\circ} \mathrm{C}$ dan mengalami kenaikan 16,72 cSt menjadi 22,36 cSt pada suhu $100^{\circ} \mathrm{C}$ untuk minyak nabati murni. Untuk nilai pH mengalami penurunan dari dari pH 7,8 menjadi 5,7.

3. Kinerja minyak jarak (castor oil) dengan penambahan Oil Additive And Ceratec Liqui 
Moly dari hasil pengujian untuk menggantikan minyak bumi mineral sebagai oli pelumas bisa lebih maksimal jika banyak produsen minyak pelumas di Indonesia memanfaatkan hasil alam untuk memodifikasi bahan kandungan lainnya untuk menjadi minyak pelumas yang baik dan harga lebih terjangkau

4. Mesin agak sedikit panas di jarak tempuh diatas $825 \mathrm{~km}$, dikarenakan agak berkurangnya jumlah minyak pelumas didalam bak mesin

5. Massa oli cenderung menurun dikarenakan zat aditif berkerja dengan maksimal mampu melummasi setiap ruang pada gigi transmisi pada mesin sehingga meminimalisir adanya geram maupun endapan lumpur

6. Minyak jarak (castor oil) dengan penambahan Oil Additive And Ceratce Liqui Moly menghasilkan emisi gas buang yang ramah lingkungan dikarenakan menghasilkan HC dan CO yang minim bahkan memenuhi standart emisi Euro III

\subsection{Saran}

1. Temperatur sangat berpengaruh terhadap penurunan dan kenaikan dari kekentalan, oleh karena itu dibutuhkan alat instrumen berbasis digital untuk mengukur kekentalan minyak pelumas agar mendapatkan hasil yang akurat.

2 Perlu penelitian untuk mengembangkan zat aditif dari dalam negeri untuk bisa mempertahankan nilai dari bilangan asam (TAN) dan bilangan basa (TBN) dikarenakan penurunan kekentalan sangat berpengaruh pada nilai keasaman dari minyak pelumas tersebut

3. Diperlukan penelitian lanjutan dengan komponen komponen mesin yang lebih baik untuk menunjang jarak tempuh yang lebih jauh dan melakukan analisa terhadap kondisi mesin kendaraan setelah pengujian menggunakan minyak jarak dengan campuran zat aditif.

4. Dibutuhkan zat aditif yang diproduksi dalam negeri agar biaya lebih terjangkau dan mampu menjaga kestabilan oli lebih baik lagi untuk menjaga performance mesin.

5. Dibutuhkan zat aditif khusus untuk menjaga nilai keasaman $\mathrm{pH}$ yang bisa dikembangkan oleh produsen minyak pelumas dalam negeri untuk meminimalisir biaya.

6. Memodifikasi komponen mesin untuk memenuhi emisi gas buang standart Euro IV seperti di ruang bakar seperti piston dan lapisan dinding silinder dan di gearbox agar meminimalisir penguapan minyak pelumas. 